\title{
Peptide bound hypohydroxyprolinuria in Handigodu Disease: A familial syndrome of spondylo epi(meta)physeal dysplasia
}

\author{
Mallikarjun Badadani ${ }^{\mathrm{a}, *}$, S.V. Suresh Babu ${ }^{\mathrm{a}}$, K.T. Shetty ${ }^{\mathrm{a}}$ and S.S. Agarwal ${ }^{\mathrm{b}}$ \\ ${ }^{a}$ Department of Neurochemistry, National Institute of Mental Health and Neuro Sciences, Bangalore-560029, India \\ ${ }^{\mathrm{b}}$ Advanced Center for Treatment Research and Education in Cancer (ACTREC) Navi Mumbai, India
}

\begin{abstract}
Handigodu Disease (HD) is disorder of the osteoarticular system prevalent in few villages of two districts of the state Karnataka in southern India. 24 hrs urinary excretions of proline (Pro) and 4-hydroxyproline (Hyp) were analyzed by HPLC. Decreased peptide bound Hyp excretions ( $\mu$ mole $/ 24 \mathrm{hrs}$ ) were found in patient group when compared with controls (Nonaffected; $113.02 \pm 67.96$, Type-I; $36.22 \pm 20.76$, Type-II; $45.74 \pm 14.95$, Type-III; $40.46 \pm 22.68$ ) and without significant difference in Pro excretions. Significant increased peptide bound Pro to Hyp ratio were found in patient group compared to control (Nonaffected $n=63: 2.02 \pm 1.65$, Type-I $n=18: 3.144 \pm 1.42$, Type-II $n=28: 4.21 \pm 1.95$, Type-III $n=8: 8.60 \pm 6.55$ ). 24 hrs urinary excretions of deoxypyridinoline (DPD) crosslinks were found without significant difference among affected and control, hence HD ruled out from general bone reduction. These results suggest hypohydroxyprolinuria may be because of reduced bone turnover or defective hydroxylation of prolyl residues during post translational modification of collagen biosynthesis.
\end{abstract}

Keywords: Handigodu disease, peptide bound, hypohydroxyprolinuria, dinitrophenyl

\section{Introduction}

Handigodu Disease (HD) is a disorder of the osteoarticular system prevalent in several villages of two districts Shimoga and Chickmaglur in the state of Karnataka, southern India. The disease was first identified in a patient from Handigodu village in 1975, hence its name [1]. HD is a spondylo epi(meta)physeal dysplasia inherited as an autosomal dominant trait and identified to be of three types viz., Arthritic type (Type-I), Dysplastic type (Type-II) and Dwarf type (Type-III). All three types segregate in the same families.

The symptoms usually start in young adulthood with pain in hip joints area and difficulty in walking and running. The onset is insidious and course progressive,

${ }^{*}$ Corresponding author: Present address: Pediatrics Dept., 2501, Hewitt Hall, Irvine, University of California, Irvine, CA-92697, USA. Tel.: +1 903618 9413; Fax: +1 949824 6388; E-mail: badadani@gmail.com; mbadadan@uci.edu. significantly handicapped with osteoarthritis of the hip joints by 35-45 yrs of age. Fixed flexion deformity of hips, lumbar lordosis, waddling gait, difficulty in squatting and sitting cross-legged are more common in patients. Type I individuals are usually of normal height and proportions, Type II individuals have significant truncal shortening and marked platyspondyly and Type III individuals are dwarf and show epiphyseal dysplasia at knee, wrists and other joints [2,3].

The major groups of spondyloepiphyseal dysplasias which were similar to HD are SED congenita, SED tarda and pseudoachondrodysplasia. HD is different from these dysplasias in several aspects either clinical presentation or in X-ray analysis [2]. The Namaqualand hip dysplasia is an autosomal dominant SED tarda, from South Africa has similar clinical presentation to HD. Posterior hump in spine is absent and knees were not been deformed in Namaqualand hip dysplasia has made a differ from HD. The disease found in South Africa namely MSeleni joint disease had clinical 
Table 1

Urinary excretion of Total amino acids, Free amino acids in Handigodu patients in relation to 24 hrs urine volume and creatinine

\begin{tabular}{lcccc}
\hline & Nonaffected & Type-I & Type-II & Type-III \\
\hline \multirow{4}{c}{ mmoles / 24 hrs } \\
Total amino acids & $18.63 \pm 5.76$ & $18.21 \pm 4.48$ & $22.01 \pm 10.29$ & $20.78 \pm 10.92$ \\
Free amino acids & $5.68 \pm 2.59$ & $5.08 \pm 1.84$ & $6.61 \pm 2.71$ & $5.16 \pm 1.68$ \\
Peptide bound amino acids & $12.94 \pm 4.15$ & $12.63 \pm 3.93$ & $13.5 \pm 8.24$ & $12.82 \pm 4.11$ \\
& mmoles / mmole cratinine & & \\
Total amino acids & $5.46 \pm 2.11$ & $5.26 \pm 1.76$ & $4.15 \pm 1.53$ & $5.33 \pm 2.89$ \\
Free amino acids & $1.63 \pm 1.30$ & $1.658 \pm 0.741$ & $1.346 \pm 0.408$ & $1.387 \pm 0.518$ \\
Peptide bound amino acids & $3.83 \pm 1.56$ & $3.63 \pm 1.29$ & $3.5 \pm 1.36$ & $4.07 \pm 2.58$ \\
\hline
\end{tabular}

presentations similar to HD. The only difference observed is rheumatoid arthritis like changes in metacarpophalanges and absence of posterior hump in spine in MSeleni joint disease [2]. In comparison to Stickler syndrome, HD has not affect before 5 years of age and did not manifests symptoms like cleft palate, myopia, micrognathia, reital detachment and hearing loss [4,5]. The varied clinical presentation and $\mathrm{X}$ - ray analysis of HD with other bone disorders promptly made to look into collagen metabolism.

\section{Materials and methods}

\subsection{Subjects}

The HD affected patients clinically and x-ray radiologically confirmed (Type-I; $n=19$, Type-II; $n=$ 28 . Type-III; $n=8$.) have been selected for this study under the age group of 20-60 years old with their consent. Sixty three (Nonaffected: $n=63$ ) healthy individuals with age group of 20-60 years old from the non related family members of HD affected were enrolled in this study as controls. All the controls clinical and by $\mathrm{x}$-ray diagnosis were normal. Both the affected and control groups have been provided normal food that has not contain any collagen products during the study. The subjects were asked to empty their bladder before the experiments of $24 \mathrm{hrs}$ urine collection started. The 24 hours urine was collected using Conc $\mathrm{HCl}$ as preservative to avoid microbial deterioration.

\subsection{Biochemical markers}

The 24 hour urine samples were collected and stored at $-20^{\circ} \mathrm{C}$ until they were analyzed. The urinary excretion of creatinine has been assayed by autosampler in the department. (Hitachi 905). Excretions of Deoxypyridinoline (DPD) crosslinks levels in urine were determined by DPC Immulite-2000 reagents and relat- ed to 24 hrs urine volume. The urine has been subjected to alkaline hydrolysis to analyze total proline (Pro), total hydroxyproline (Hyp) and total amino acids excreted. Free proline, free Hydroxyproline and free amino acids excreted were assayed without hydrolysis. The peptide bound proline, peptide bound hydroxyproline, and peptide bound amino acids were calculated by deducting free from total. The peptide bound Pro and Hyp were made free by the hydrolysis of urine following the procedure of M. Badadani et al. [6]. Pro and Hyp were analyzed using HPLC by Dinitrophenyl derivatization using methanol and acetate buffer gradient. The Amino acids were quantified by using the method of DNFB $[7,8]$. The total as well as peptide bound Hyp, Pro and amino acids excreted were calibrated to $24 \mathrm{hrs}$ urine volume collected and, Pro and Hyp were related to creatinine and amino acids.

\subsection{Statistical analysis}

The Data were analyzed using SPSS programme of Windows 2000 and statistical significance of the correlation was determined with one- way ANOVA followed by Post Hoc, Bonferroni T-test. The $\mathrm{P}$ values indicate significance level of differences between the means at point. The probability values less than 0.05 were considered statistically significant.

\section{Results}

The excretion of Deoxypyridinoline (DPD) crosslinks ( $\mu$ mole/24 hrs) \{Nonaffected: $44.28 \pm 27.99$, Type-I: $46.62 \pm 15.7$, Type-II: $49.87 \pm 16.03$, Type-III: $51.03 \pm 16.22\}$ values found without significant difference as shown in Fig. 1. Since comparison of Excretions of free amino acids, free Pro and free Hyp between affected and unaffected groups have not shown significant difference and data were presented in Tables 1 and 2 . 

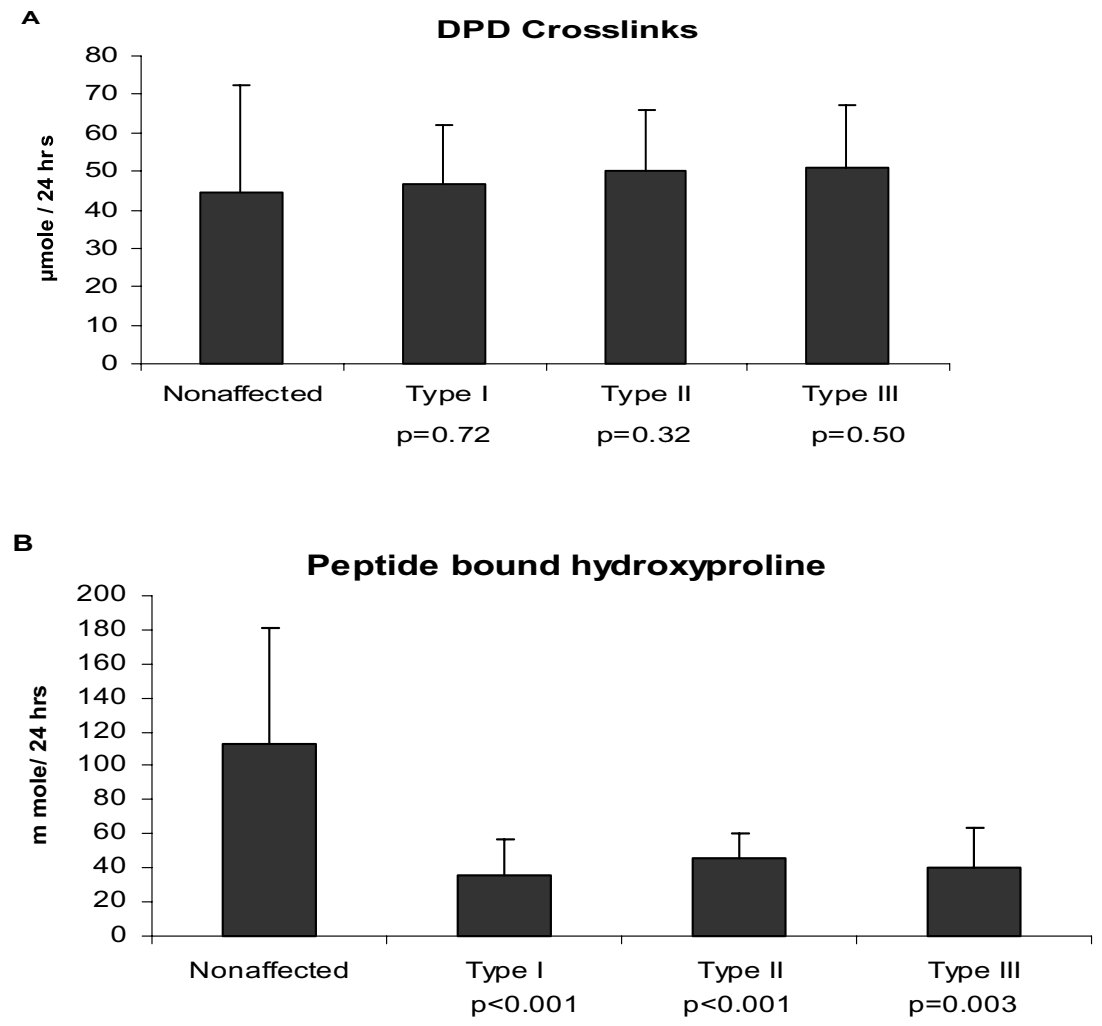

C

Proline / Hydroxyproline ratio

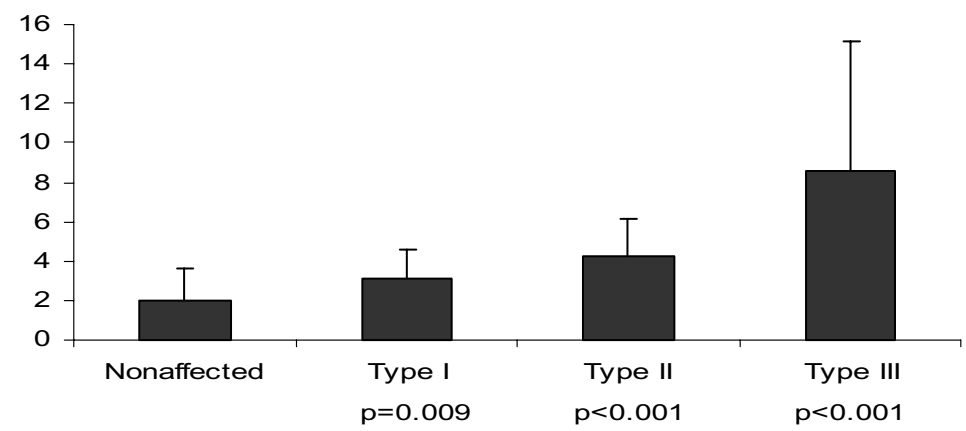

Fig. 1. A. 24 hrs urinary excretions of deoxypyridinoline (DPD) crosslinks among Nonaffected and affected subtypes showing without significant difference. B. 24 hrs urinary excretions of peptide derived hydroxyproline among Nonaffected and clinical subtypes showing significant difference with depleted levels in HD affected. C. Urinary excretions of peptide derived proline / hydroxyproline ratio among unaffected and affected subtypes showing significant difference with elevated levels in HD affected.

The Excretions of total as well as peptide bound amino acids, Pro and Hyp were presented in Table 2 .The values have related to aminoacids, creatinine excreted and $24 \mathrm{hrs}$ urine volume collected. The affected groups have excreted depleted level of Hyp in comparison with unaffected group. The values of ratio between Pro and Hyp were compared and found to be significantly higher in affected groups than control with

$$
p<0.05 \text { (Fig. 2) }
$$

\section{Discussion}

The Hydroxyproline (Hyp) constitutes 12-14\% amino acid content of matured collagens, but only $10 \%$ released during the bone resorption reaches the urine 
Table 2

Urinary excretion of Total Proline, Total Hydroxyproline Free Proline, free Hydroxyproline, peptide bound proline, peptide bound hydroxyproline Pro / Hyp Ratio in relation to 24 hrs urine volume (table 2A), creatinine (table2B) and amino acids (table2C) excreted in Handigodu patients

\begin{tabular}{|c|c|c|c|c|}
\hline Panel A & Nonaffected & Type-I & Type-II & Type-III \\
\hline \multicolumn{5}{|c|}{$\mathrm{m}$ mole / 24 HRS } \\
\hline Total Proline & $177.80 \pm 61.44$ & $\begin{array}{c}124.19 \pm 74.5 \\
p=0.002\end{array}$ & $\begin{array}{c}189.05 \pm 88.04 \\
p=0.495\end{array}$ & $\begin{array}{c}188.09 \pm 111.97 \\
p=0.691\end{array}$ \\
\hline Free Proline & $19.52 \pm 11.90$ & $\begin{array}{c}18.57 \pm 8.85 \\
p=0.741\end{array}$ & $\begin{array}{c}40.69 \pm 18.5 \\
p<0.001\end{array}$ & $\begin{array}{c}33.18 \pm 26.82 \\
p=0.010\end{array}$ \\
\hline Peptide bound Proline & $159.18 \pm 60.70$ & $\begin{array}{c}136.23 \pm 68.38 \\
p=0.164\end{array}$ & $\begin{array}{c}168.93 \pm 69.89 \\
p=0.458\end{array}$ & $\begin{array}{c}128.97 \pm 39.16 \\
p=0.176\end{array}$ \\
\hline Total Hyp & $115.09 \pm 64.99$ & $\begin{array}{c}37.43 \pm 21.34 \\
p<0.001\end{array}$ & $\begin{array}{c}48.65 \pm 17.55 \\
p<0.001\end{array}$ & $\begin{array}{c}42.23 \pm 23.01 \\
p=0.002\end{array}$ \\
\hline Free Hyp & $3.09 \pm 1.80$ & $\begin{array}{l}1.86 \pm 1.23 \\
p=0.06\end{array}$ & $\begin{array}{l}3.67 \pm 1.72 \\
p=0.154\end{array}$ & $\begin{array}{c}2.00 \pm 0.61 \\
p=0.09\end{array}$ \\
\hline Peptide bound Hyp & $113.02 \pm 67.96$ & $\begin{array}{c}36.22 \pm 20.76 \\
p<0.001\end{array}$ & $\begin{array}{c}45.74 \pm 14.95 \\
p<0.001\end{array}$ & $\begin{array}{c}40.46 \pm 22.68 \\
p=0.003\end{array}$ \\
\hline $\begin{array}{l}\text { Pro/Hyp Ratio } \\
\text { (Total) }\end{array}$ & $1.86 \pm 1.17$ & $\begin{array}{l}3.41 \pm 1.72 \\
p<0.001\end{array}$ & $\begin{array}{l}3.99 \pm 1.55 \\
p<0.001\end{array}$ & $\begin{array}{c}3.39 \pm 1.67 \\
p=0.001\end{array}$ \\
\hline $\begin{array}{l}\text { Pro/Hyp Ratio } \\
\text { (peptide bound) }\end{array}$ & $2.02 \pm 1.65$ & $\begin{array}{c}3.144 \pm 1.42 \\
p=0.009 \\
\end{array}$ & $\begin{array}{l}4.21 \pm 1.95 \\
p<0.001\end{array}$ & $\begin{array}{c}8.60 \pm 6.55 \\
p<0.001 \\
\end{array}$ \\
\hline Panel B & Nonaffected & Type-I & Type-II & Type-III \\
\hline \multicolumn{5}{|c|}{$\mu$ mole / $\mathrm{m}$ mole CREATININE } \\
\hline Total Proline & $50.55 \pm 31.81$ & $35.53 \pm 25.44$ & $35.98 \pm 19.11$ & $29.95 \pm 10.59$ \\
\hline Free Proline & $5.40 \pm 3.39$ & $4.75 \pm 1.83$ & $6.48 \pm 3.40$ & $3.80 \pm 1.68$ \\
\hline Peptide bound Proline & $45.93 \pm 31.15$ & $35.07 \pm 20.15$ & $36.04 \pm 18.48$ & $38.35 \pm 14.94$ \\
\hline Total Hyp & $34.48 \pm 27.81$ & $11.97 \pm 8.62$ & $9.23 \pm 3.46$ & $8.85 \pm 4.17$ \\
\hline Free Hyp & $0.52 \pm 0.30$ & $0.862 \pm 0.851$ & $0.923 \pm 0.633$ & $0.371 \pm 0.223$ \\
\hline Peptide bound Hyp & $33.47 \pm 27.52$ & $12.80 \pm 8.44$ & $8.54 \pm 3.33$ & $9.62 \pm 3.12$ \\
\hline $\begin{array}{l}\text { Pro/Hyp Ratio } \\
\text { (Total) }\end{array}$ & $1.86 \pm 1.56$ & $3.29 \pm 1.74$ & $3.92 \pm 1.57$ & $3.39 \pm 1.67$ \\
\hline $\begin{array}{l}\text { Pro/Hyp Ratio } \\
\text { (peptide bound) }\end{array}$ & $2.00 \pm 1.64$ & $3.43 \pm 1.45$ & $4.14 \pm 1.95$ & $8.24 \pm 6.79$ \\
\hline Panel C & Nonaffected & Type-I & Type-II & Type-III \\
\hline \multicolumn{5}{|c|}{$\mu$ mole $/ \mathrm{m}$ mole Amino acids } \\
\hline Total Proline & $10.55 \pm 5.48$ & $8.11 \pm 5.19$ & $9.89 \pm 4.56$ & $9.08 \pm 2.8$ \\
\hline Free Proline & $3.26 \pm 1.96$ & $3.74 \pm 2.37$ & $5.38 \pm 2.05$ & $4.98 \pm 3.32$ \\
\hline Peptide bound Proline & $7.41 \pm 5.83$ & $6.52 \pm 3.98$ & $8.57 \pm 4.15$ & $8.75 \pm 2.85$ \\
\hline Total Hyp & $6.82 \pm 5.20$ & $2.46 \pm 1.47$ & $2.61 \pm 0.99$ & $2.42 \pm 1.67$ \\
\hline Free Hyp & $1.14 \pm 0.73$ & $1.48 \pm 1.03$ & $3.95 \pm 1.77$ & $2.009 \pm 0.61$ \\
\hline Peptide bound Hyp & $6.18 \pm 4.97$ & $1.76 \pm 1.39$ & $2.14 \pm 1.08$ & $1.83 \pm 0.87$ \\
\hline $\begin{array}{l}\text { Pro/Hyp Ratio } \\
\text { (Total) }\end{array}$ & $1.85 \pm 1.49$ & $3.50 \pm 1.74$ & $3.99 \pm 1.55$ & $3.39 \pm 1.67$ \\
\hline $\begin{array}{l}\text { Pro/Hyp Ratio } \\
\text { (peptide bound) }\end{array}$ & $2.05 \pm 1.89$ & $3.5 \pm 1.73$ & $3.99 \pm 1.55$ & $8.23 \pm 6.16$ \\
\hline
\end{tabular}

in free or peptide forms [9]. Since most of the Hyp of body is found in collagen and suggested that urinary excretion of this imino acid may be an important index of collagen metabolism [10-12]. The isotopic studies of Stetten in rats indirectly suggested that most of the free and peptide bound Hyp in the body arises from the breakdown of collagen, since she found that hyp-N15 was not significantly incorporated into collagen [13]. The diurnal variation, hydration and dehydration did not alter excretion of Hyp. The ingestion of large amounts of Hyp as free imino acid resulted in an increased excretion of free but not in the peptide form which normally accounts for nearly all of Hyp in urine $[10,12]$. Westall described a peptide containing equal amounts of Pro and Hyp and the bound Hyp form that predominates in human urine [14]. The urine of a patient with rheumatoid arthritis had shown two hyp bound peptides [15]. The study has been made of peptide excretion in Wilson's disease, excess output of peptide was shown to consist of Hyp peptides derived from collagen degradation was highly statistically significant [16].

The 24 hrs urinary excretions of DPD crosslinks have shown without significant difference, hence HD has 
been ruled out from general reduction of bone resorption. The values for excretions of Pro and amino acids either in total, free or peptide form found without significant difference. The free Hyp excreted were also found to be normal. Hence their diet and diurnal variation have not been influenced on the excretion of Pro and Hyp in HD. The depleted levels of Hyp in $24 \mathrm{hrs}$ urine, in relation to creatinine and amino acids excreted either in total form or peptide bound (Nonaffected: $113.02 \pm 67.96 \mu$ mole / $24 \mathrm{hrs}$, TypeI: $36.22 \pm 20.76 \mu$ mole / 24 hrs, Type II:45.74 $\pm 14.95 \mu$ mole / 24hrs, TypeIII: $40.46 \pm 22.68 \mu$ mole / $24 \mathrm{hrs}$ ) were observed in affected group. In addition increased Pro/Hyp ratios were observed in HD group as compoared to unaffected group (Fig. 1). The results are consistent with the hypothesis that large hyp excretions found in rheumatic diseases Marfan's syndrome and Stickler syndrome [4, $10,11]$. For many years, measurement of $24 \mathrm{hrs}$ or second morning void urinary Hyp / creat has been used successfully as an index of bone collagen resorption. Elevated levels of hyp urinary excretions have been found in Paget disease [17]. A variety of biochemical tests reflecting bone matrix resorption provide good indices of disease activity. Handigodu Disease is the only first most disease reporting lesser excretions of Hydroxyproline in urine compared to other bone disorders like Marfan's syndrome, Paget disease, secondary hyperthyroidism rheumatoid arthritis and Stickler syndrome that have shown elevated levels.

The peptide bound hypohydroxyprolinuria and increased Pro / Hyp ratio suggests HD may involve reduced bone turnover or a possible defective hydroxylation of prolyl residues during posttranslational modification of collagen molecule biosynthesis. Hence possible defect in prolyl-4- hydroxylases activity and possible defect in collagen assembly as Hyp is necessary for the stability of collagen molecule [18]. Apart from hypohydroxyprolinuria, HD has shown hypocalcitonemia (manuscript submitted). Hence HD appears to be a multigene disorder with varied involvement of genes and clinical presentation.

The limitation of study is that Pro and Hyp excretion levels analysis should be extended to other dysplasia bone disorders and follow up study is needed to understand progression of severity in HD.

\section{Acknowledgements}

Authors thank the social workers, Shri.Chandrashekhar Bhat and Smt.Rajaratnakka Bhat, in mobiliz- ing the cooperation of patients and their families. Dr. B.G. Sangam, Chief Medical Officer, Sagar Taluq Hospital, was responsible for getting the patients admitted in the hospital for collection of 24 hour urinary samples. Authors are also thankful to Directorate of Health Services, Govt of Karnataka for providing logistic support for the study. Authors are extremely thankful to the patients and family members for their cooperation. The study was supported by the ICMR Research Grant 48/1/2000.BMS received from the Indian Council of Medical Research for Handigodu Disease Phase II, and the Senior Research Fellowship (45/24/2003/Bio/BMS) received from the Indian Council of Medical Research.

\section{References}

[1] R.V. Bhat and KVAR, Krishnamachari.Endemic familial arthritis of Malnad, Indian J Med Res 66 (1977), 777-786.

[2] S.S. Agarwal, S.R. Phadke, R.V. Phadke, S.K. Das, G.K. Singh, J.P. Sharma, SPS. Teotia and B.N. Saxena, Handigodu disease. A radiological study, Skeletal Radiol 23 (1994), 611-619.

[3] S.S. Agarwal, S.R. Phadke, V. Fredlund, D. Viljoen and P. Beighton, Mseleni and Handigodu Familial Osteoarthropathies: Syndromic Identity? Am J Med Gen 72 (1997), 435-439.

[4] S.J. Popkin and R.C. Polomeno, Stickler syndrome, Heriditory progressive arthro-ophthalmopathy, Canadian Med Assoc Journal 111 (1974), 1071-1076.

[5] L. Olavarrieta, C. Morales-Angulo, I. del Castillo, F. Moreno and M.A. Moreno-Pelayo, Stickler and branchio-otro-renal syndromes in a patient with mutations in EYA1 and COL2A1 genes, Clin Genet 3(3) (2008), 262-267.

[6] M. Badadani, S.V. Suresh Babu and K.T. Shetty, Optimum conditions of autoclaving for hydrolysis of proteins and urinary peptides of prolyl and hydroxyprolyl residues and HPLC Analysis, J Chrom B 847(2) (2007), 267-274.

[7] M. Badadani, S.V. Suresh Babu and K.T. Shetty, Dinitrophenyl Derivatization of Imino Acids, Spectral Characteristics and HPLC Analysis: Application in Urinary Peptide Derived Hydroxyproline and Proline Assay, Annal Clin Biochem 43(2) (2007), 164-172.

[8] H. Varley, A.H. Gowenlock and M. Bell, Amino acid nitrogen, in: Practical Clinical Biochemistry, (Vol-I), (5th edn), The White Friars Press, London. William Heinemann Medical Books Ltd, 1980, pp. 490-494.

[9] P.D. Delmas, R. Eastell, P. Garnero, M.J. Siebel and J. Stepan, The use of biochemical markers of turn over in osteoporosis, Osteoporosis International 6(suppl) (2000), S2-S17.

[10] M. Ziff, A. Kibrick, E. Dresner and H. Gribetz, Excretion of hydroxyproline in patients with rheumatic and non-rheumatic diseases, J clin Invest 35 (1956), 579-587.

[11] A. Sjoerdsma, J.D. Davidson, S. Udenfriend and C. Mitoma, Increased excretion of hydroxyproline in Marfan's syndrome, Lancet 2 (1958), 994.

[12] D.J. Prockop and A. Sjoerdsma, Significance of urinary hydroxyproline in man, J Clin Invest 42 (1961), 843-849. 
[13] M.R. Stetten, Some aspects of the metabolism of hydroxyproline, studied with the aid of isotopic nitrogen, J Biol Chem 181 (1949), 31-37.

[14] R.G. Westall, The amino acids and other ampholytes of urine. Three unidentified substances excreted in normal human urine, Biochem J 60 (1955), 247-255.

[15] G. Mechanic, S.J. Skupp, L.B. Safier and A.C. Kibrick, Isolation of two peptides containing hydroxyproline from urine of a patient with rheumatoid arthritis, Arch Biochem 86 (1960), $71-76$
[16] A.M. Asatoor, M.D. Miline and J.M. Walshe, Urinary excretion of peptides and of hydroxyproline in Wilson's disease, Clin Sci Mol Med 51 (1976), 369-378.

[17] W.L. Kenneth, S.S. Ethel, R.S. Frederick and J.M. Pierre, A Clinical Approach to Diagnosis and Management of Paget's Disease of Bone, J Bone Miner Res 16 (2001), 1379-1387.

[18] N.G. Ramachandran and M. Keneth, Structure of collagen, Nature 176 (1955), 593-595. 


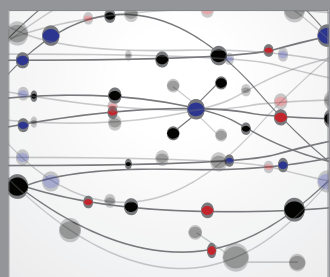

The Scientific World Journal
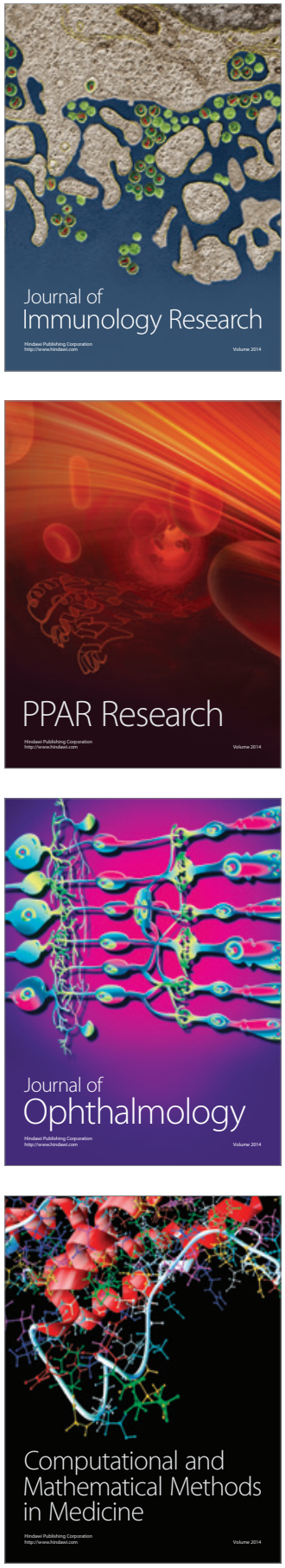

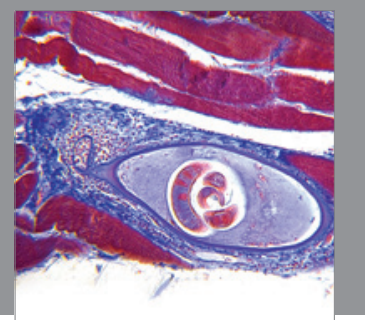

Gastroenterology

Research and Practice
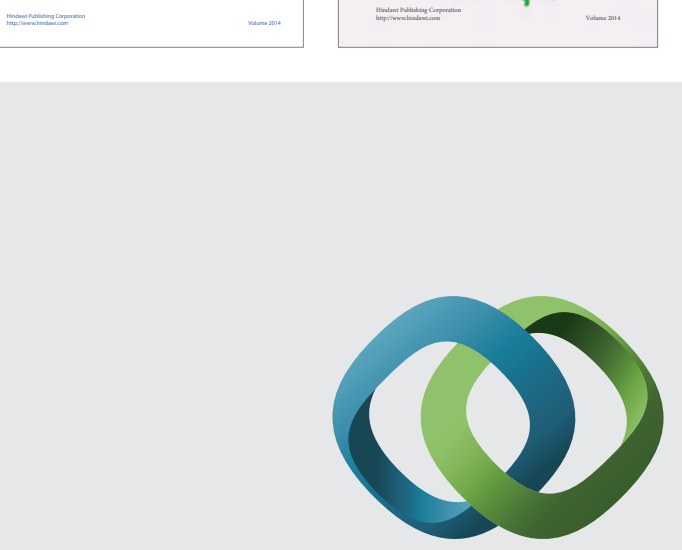

\section{Hindawi}

Submit your manuscripts at

http://www.hindawi.com
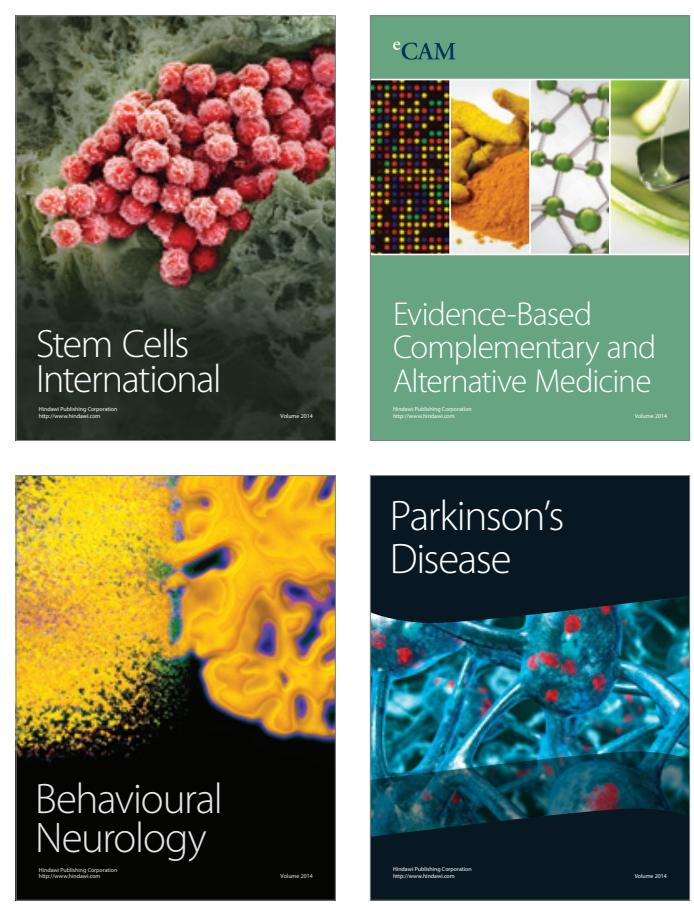

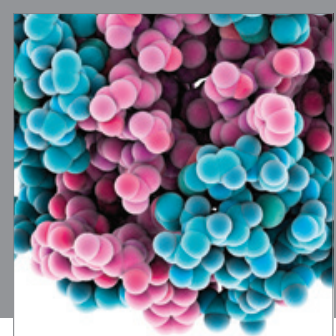

Journal of
Diabetes Research

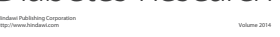

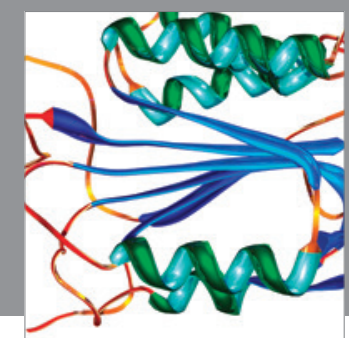

Disease Markers
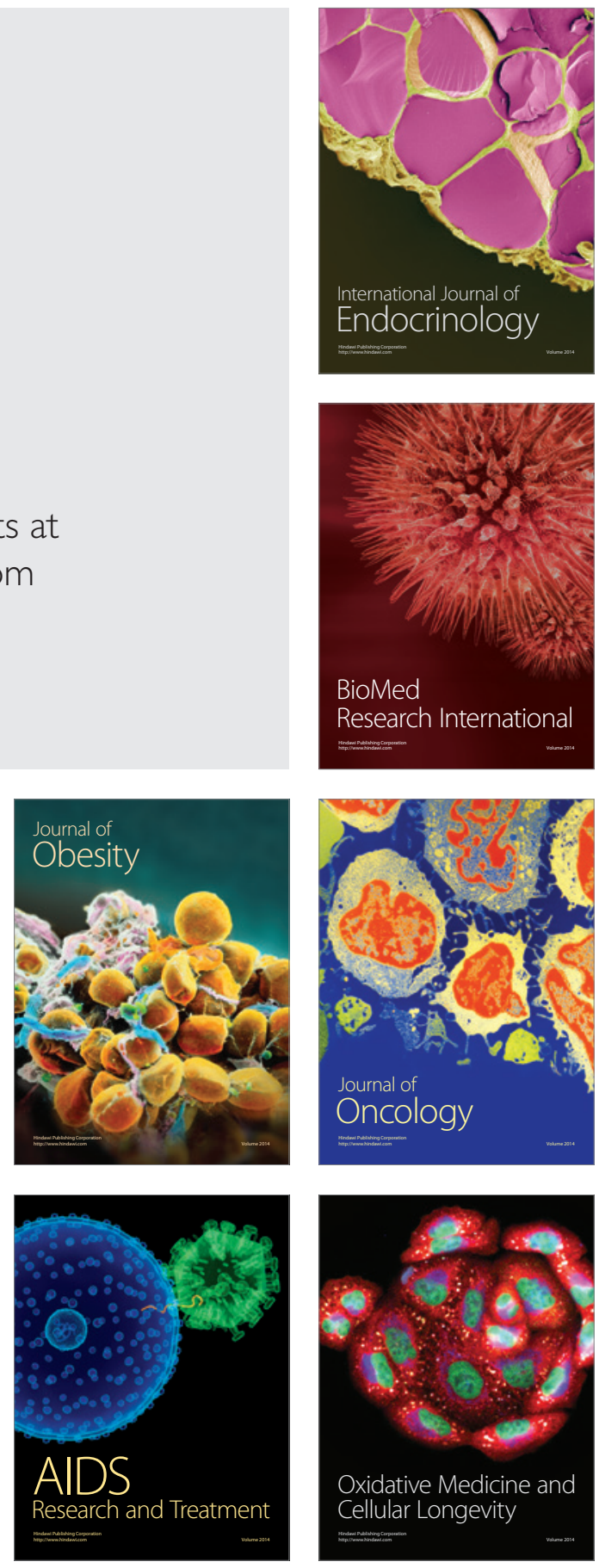